- Original Article

\title{
Factors Associated with the Intention to Quit Smoking in Elderly Korean Men: The Korea National Health and Nutrition Examination Survey 2010-2015
}

Inho Lee, Yong Soon Park*, Jeong Hyeon Kim, Seung Hyeok Han

Department of Family Medicine, Hallym University Chuncheon Sacred Heart Hospital, Chuncheon, Korea

Background: Tobacco smoking is the most preventable cause of diseases and death in older adults. This study aimed to evaluate the factors associated with the intention to quit smoking in elderly Korean men.

Methods: We investigated 813 male smokers aged 65 years or more from the 5th and 6th Korea National Health and Nutrition Examination Survey 2010-2015. Multiple logistic regression analysis was performed to identify factors related with smoking cessation intention.

Results: Of the respondents, $26.3 \%$ had the intention to quit smoking. After adjustment for confounding factors, the intention to quit smoking was significantly associated with a history of ischemic heart disease (adjusted odds ratio, 1.88 ; $95 \%$ confidence interval, $1.02-3.48$ ).

Conclusion: Identifying the factors related to the intention to quit smoking among older adults can help in developing effective smoking cessation strategies for this section of the population.

Keywords: Smoking Cessation; Intention; Aged; Korea National Health and Nutrition Examination Survey

Received: July 30, 2018, Revised: January 26, 2019, Accepted: January 28, 2019

*Corresponding Author: Yong Soon Park https://orcid.org/0000-0002-8926-9836

Tel: +82-33-240-5311, Fax: +82-33-240-5440, E-mail: pyongs@hallym.or.kr 


\section{INTRODUCTION}

Tobacco smoking is known to be the leading cause of premature death in older adults by increasing the incidence of cancer, cardiovascular diseases, and respiratory diseases worldwide. ${ }^{1)}$ In Korea, smoking-related diseases are a major cause of death in old people. ${ }^{2)}$ Although the rate of smoking in Korean elderly people aged 65 years or above is decreasing year by year, declining to $10.2 \%$ in $2017,{ }^{3)}$ it is expected that the number of elderly smokers will continue to grow due to population aging. ${ }^{2)}$ The resulting socio-economic cost is an added burden. ${ }^{4)}$

To date, the Korean government has implemented a variety of smoking cessation policies. However, the rate of quitting attempts among older Korean smokers is lower than among other adult age groups. ${ }^{5)}$ A major reason is that elderly smokers are highly addicted to nicotine and are not aware of smoking cessation resources. ${ }^{6,7)}$ Additionally, they have a misperception that the health benefits from smoking cessation will be small. ${ }^{8}$ In fact, smoking cessation among elderly smokers has clear and considerable health benefits; it reduces the incidence of cancer, and cardiovascular and respiratory diseases, and positively affects recurrence rate, survival rate, treatment, and quality of life after onset. ${ }^{9}$

Smoking cessation is most effective when voluntary motivation is induced in the smoker. According to the trans-theoretical model, having the intention to quit smoking is a prerequisite for preparing and implementing smoking cessation. ${ }^{10)}$ In a previous study, it was reported that smokers had a higher rate of quitting attempts if they had smoking cessation intentions. ${ }^{11)}$ Therefore, identifying factors related to the intention to quit smoking is critical for establishing an effective smoking cessation strategy.

Although studies on the intention to quit smoking have been conducted in many countries including Korea, most of these studies were confined to specific areas. ${ }^{12)}$ Furthermore, since most of the studies addressed the entire adult population, it was not easy to understand the factors associated with smoking cessation intentions in older adults. Therefore, in this study, we aimed to identify the various factors related to the intention to quit smoking among elderly Korean men using the Korea National Health and Nutrition Examination Survey (KNHANES) data representing the Korean population.

\section{METHODS}

\section{Study Population}

This study was based on the 5th and 6th KNHANES conducted from 2010 to 2015 by the Korea Centers for Disease Control and Prevention.

Table 1. Comparison between elderly Korean men with and without intention to quit smoking

\begin{tabular}{|c|c|c|c|c|c|c|c|}
\hline \multirow[t]{2}{*}{ Characteristic } & \multicolumn{2}{|c|}{ Total } & \multicolumn{2}{|c|}{$\begin{array}{l}\text { With intention to quit smoking } \\
\qquad(\mathrm{n}=239)\end{array}$} & \multicolumn{2}{|c|}{$\begin{array}{l}\text { Without intention to quit smoking } \\
\qquad(\mathrm{n}=732)\end{array}$} & \multirow[t]{2}{*}{ P-value } \\
\hline & No. (weighted \%) & SE & No. (weighted \%) & SE & No. (weighted \%) & SE & \\
\hline Age (y) & & & & & & & 0.900 \\
\hline $65-69$ & $344(42.6)$ & 2.0 & $97(44.0)$ & 3.9 & $247(42.1)$ & 2.4 & \\
\hline $70-74$ & $254(30.5)$ & 2.0 & $60(29.2)$ & 3.8 & $194(31.0)$ & 2.2 & \\
\hline$\geq 75$ & $215(26.9)$ & 1.9 & $57(26.8)$ & 3.6 & $158(27.0)$ & 2.2 & \\
\hline Marital status: single & $113(13.8)$ & 1.4 & $23(14.0)$ & 3.0 & $90(13.7)$ & 1.6 & \\
\hline Education level: $\leq$ middle school & $549(69.8)$ & 1.8 & $131(62.8)$ & 4.0 & $418(72.2)$ & 2.0 & 0.032 \\
\hline Economic inactivity or unemployed & $416(53.3)$ & 2.2 & $115(56.1)$ & 4.1 & $301(52.3)$ & 2.5 & 0.423 \\
\hline Living alone & $100(10.8)$ & 1.2 & $18(8.7)$ & 2.1 & $82(11.5)$ & 1.4 & 0.283 \\
\hline Monthly alcohol drinking & $529(64.6)$ & 1.9 & $130(61.3)$ & 4.1 & $399(65.8)$ & 2.1 & 0.339 \\
\hline Regular walking: no & $478(61.1)$ & 2.1 & $128(61.9)$ & 4.0 & $350(60.8)$ & 2.4 & 0.824 \\
\hline Stress: yes & $134(15.6)$ & 1.6 & $42(19.8)$ & 3.3 & $92(14.1)$ & 1.7 & 0.085 \\
\hline \multicolumn{8}{|l|}{ Current medication } \\
\hline Hypertension & $324(42.8)$ & 2.1 & $87(42.5)$ & 4.3 & $237(42.9)$ & 2.4 & 0.939 \\
\hline Diabetes & $157(19.2)$ & 1.6 & 44 (18.3) & 2.8 & $113(19.5)$ & 1.9 & 0.716 \\
\hline Dyslipidemia & $72(9.0)$ & 1.2 & $20(9.3)$ & 2.2 & $52(8.9)$ & 1.4 & 0.899 \\
\hline \multicolumn{8}{|l|}{ Medical history } \\
\hline Stroke & $51(6.5)$ & 1.0 & $15(6.8)$ & 1.9 & $36(6.4)$ & 1.1 & 0.836 \\
\hline Ischemic heart disease & $54(6.8)$ & 1.0 & $20(10.2)$ & 2.4 & $34(5.5)$ & 1.0 & 0.034 \\
\hline Cancer & $44(4.8)$ & 0.8 & $16(7.2)$ & 1.8 & $28(4.0)$ & 0.9 & 0.070 \\
\hline Depression & $19(3.8)$ & 0.9 & $5(3.9)$ & 1.9 & $14(3.8)$ & 1.1 & 0.967 \\
\hline Pulmonary tuberculosis & $66(14.8)$ & 1.8 & $24(19.3)$ & 4.0 & $42(13.0)$ & 2.0 & 0.144 \\
\hline Asthma & $35(7.3)$ & 1.4 & $12(9.0)$ & 2.8 & $23(6.7)$ & 1.6 & 0.460 \\
\hline Chronic obstructive pulmonary disease & $20(2.4)$ & 0.6 & $8(3.5)$ & 1.4 & $12(2.0)$ & 0.6 & 0.286 \\
\hline Health screening: no & $306(37.6)$ & 2.0 & $69(32.5)$ & 4.0 & $237(39.4)$ & 2.3 & 0.137 \\
\hline Cancer screening: no & $384(48.7)$ & 2.2 & $93(43.8)$ & 4.2 & $291(50.5)$ & 2.5 & 0.167 \\
\hline Pulmonary function test: abnormal finding & $341(73.6)$ & 2.4 & $100(74.5)$ & 4.5 & $241(73.2)$ & 2.8 & 0.802 \\
\hline
\end{tabular}

P-values were determined using the chi-square test.

SE, standard error. 
From among the participants aged 65 years and older, we analyzed the data of 813 respondents who were men who currently smoked, and answered the questionnaire about the intention to quit smoking. All participants in this survey signed an informed consent form, and the KNHANES was reviewed and approved by the KCDC Institutional Review Board (2010-02CON-21-C, 2011-02CON-06-C, 2012-01EXP-012C, 2013-07CON-03-4C, and 2013-12EXP-03-5C).

\section{Definition of Intention to Quit Smoking}

Intention to quit smoking was measured by asking, "Are you planning to quit smoking?" The four possible answers were "within the next month," "within the next 6 months," "sometime in the future, beyond 6 months," and "not planning to quit." Only the response of "within the next month" qualified as having an intention to quit smoking; the remaining responses did not.

\section{Other Variables}

We assessed variables related to socio-economic characteristics including age, marital status, education level, economic status, and living condition. Current age was classified into three ranges: 65-69 years, 70-74 years, and 75 years and above. Marital status was classified as single or married; single included never married, divorced, widowed, or separated from a spouse. Education level was classified as middle school graduation or lower, and high school graduation or higher. Economic activity was classified as active or employed, and inactive or unemployed. Living condition was classified as living alone or living with other people.

We assessed variables related to smoking and health, including alcohol consumption, regular walking, and health screening. Monthly alcohol consumption was classified as none or 1 or more glass of alcohol per month. Regular walking was defined as walking at least 5 times per week for 30 or more minutes per session. Perceived stress was measured by asking, "How much stress are you experiencing in your daily life?"; the four possible answers were very low, low, high, and very high, and only the responses of high or very high were defined as having perceived stress. Data regarding current medication for hypertension, diabetes, and dyslipidemia were collected. Medical history of stroke, ischemic heart disease, cancer, depression, pulmonary tuberculosis, chronic obstructive pulmonary disease (COPD), and asthma were assessed by questions asking whether or not the participants had received a diagnosis of these diseases from a doctor. Health and cancer screening were defined as having undergone screening more than once during the past 2 years. Pulmonary function test was defined as normal when the examined participants were judged to be normal, and abnormal when diagnosed as having restrictive or obstructive ventilation.

\section{Statistical Analysis}

Statistical analyses were performed using SPSS statistical package (SPSS Inc., Chicago, IL, USA). All estimates were calculated according to sample weights, which were evaluated by taking into consideration the sampling rate, response rate, and age and sex proportions of the reference population. The analysis was adjusted for the complex sample design of the survey. Categorical data are presented as frequencies and standard errors, and the comparisons were performed using the chi-square test. Logistic regression analyses were used to identify the factors related to the intention to quit smoking in older Korean adults. Multivariable analysis model was constructed with variables with a Pvalue less than 0.1 in the univariable analysis.

\section{RESULTS}

Table 1 summarizes the general characteristics of the study population and compares diverse basic variables between participants with and without the intention to quit smoking. Among all participants, $6.5 \%$ had a history of stroke, $6.8 \%$ of ischemic heart disease, $4.8 \%$ of cancer, and $2.5 \%$ of chronic obstructive pulmonary disease. Of the 813 participants, $26.3 \%$ had smoking cessation intention. Factors significantly associated with smoking cessation intention were age, education level, stress, history of ischemic heart disease, and history of cancer.

Table 2 shows the logistic regression analysis between the intention to quit smoking and clinical variables. After adjustment for age, the in-

Table 2. Logistic regression analysis of the association between intention to quit smoking and clinical variables before adjustment and after age-adjustment

\begin{tabular}{lcc}
\hline \multicolumn{1}{c}{ Variable } & Unadjusted & Age-adjusted \\
\hline Age (y) & & \\
$\quad 65-69$ & 1 (Reference) & \\
$70-74$ & $0.90(0.60-1.51)$ & \\
$\quad \geq 75$ & $0.95(0.59-1.39)$ & \\
Marital status: single & $1.03(0.60-1.77)$ & $1.03(0.55-1.80)$ \\
Education level: smiddle school & $0.65(0.44-0.97)$ & $0.65(0.44-0.97)$ \\
Economic inactivity or unemployed & $1.17(0.80-1.70)$ & $1.20(0.82-1.74)$ \\
Living alone & $0.73(0.41-1.30)$ & $0.73(0.41-1.30)$ \\
Monthly alcohol drinking & $0.83(0.56-1.22)$ & $0.82(0.55-1.21)$ \\
Regular walking: no & $1.05(0.71-1.55)$ & $1.04(0.70-1.56)$ \\
Stress: yes & $1.51(0.94-2.41)$ & $1.50(0.94-2.39)$ \\
Current medication & & \\
$\quad$ Hypertension & & \\
$\quad$ Diabetes & $0.99(0.66-1.47)$ & $0.98(0.66-1.46)$ \\
$\quad$ Dyslipidemia & $0.92(0.60-1.42)$ & $0.92(0.60-1.42)$ \\
Medical history & $1.04(0.58-1.87)$ & $1.02(0.57-1.86)$ \\
$\quad$ Stroke & & \\
Ischemic heart disease & $1.08(0.54-2.15)$ & $1.06(0.53-2.12)$ \\
Cancer & $1.94(1.04-3.63)$ & $1.95(1.05-3.63)$ \\
Depression & $1.88(0.94-3.73)$ & $1.87(0.94-3.74)$ \\
Pulmonary tuberculosis & $1.03(0.32-3.30)$ & $1.02(0.33-3.14)$ \\
Asthma & $1.60(0.85-3.01)$ & $1.63(0.87-3.07)$ \\
Chronic obstructive pulmonary disease & $1.74(0.62-4.85)$ & $1.76(0.63-4.97)$ \\
Health screening: no & $0.74(0.50-1.10)$ & $0.74(0.49-1.10)$ \\
Cancer screening: no & $0.77(0.52-1.12)$ & $0.76(0.52-1.11)$ \\
Pulmonary function test: & $1.07(0.62-1.98)$ & $1.04(0.60-1.83)$ \\
abnormal finding & & \\
\hline
\end{tabular}

Values are presented as OR (95\% Cl). Unadjusted, age-adjusted ORs and $95 \% \mathrm{Cl}$ were estimated by the logistic regression analysis.

$\mathrm{OR}$, odds ratio; $\mathrm{Cl}$, confidence interval. 
Table 3. Multivariable adjusted evaluation of factors associated with the intention to quit smoking

\begin{tabular}{lcc}
\hline \multicolumn{1}{c}{ Variable } & OR $(95 \% \mathrm{Cl})$ & P-value \\
\hline Age $(\mathrm{y})$ & & \\
$65-69$ & 1 (Reference) & \\
$70-74$ & $0.94(0.61-1.46)$ & 0.790 \\
$\geq 75$ & $0.98(0.61-1.56)$ & 0.921 \\
Education level: smiddle school & $0.68(0.46-1.03)$ & \\
Stress: yes & $1.39(0.86-2.26)$ & 0.066 \\
Medical history & & \\
$\quad$ Ischemic heart disease & $1.88(1.02-3.48)$ & 0.045 \\
$\quad$ Cancer & $1.71(0.84-3.51)$ & 0.140 \\
\hline
\end{tabular}

Adjusted ORs and $95 \% \mathrm{Cl}$ were estimated by multiple logistic regression analysis with adjustment for all other variables.

$\mathrm{OR}$, odds ratio; $\mathrm{Cl}$, confidence interval.

crease in intention to quit smoking was statistically significant in the group with high school education or higher, and history of ischemic heart disease.

Table 3 shows the results of multivariable logistic regression analysis. After adjustment for age, educational level, stress, and past medical history, history of ischemic heart disease (odds ratio, 1.88; 95\% confidence interval, 1.02-3.48) was significantly associated with the intention to quit smoking.

\section{DISCUSSION}

This was a cross-sectional study aimed to identify the factors related to the intention to quit smoking among elderly Korean men aged 65 years or older, using data from the 5th and 6th KNHANES. Understanding the factors related to the intention to quit smoking among elderly smokers can be helpful in developing smoking cessation programs especially designed for older adults.

In previous studies, factors related to the intention to quit smoking were age, sex, education level, marital status, living condition, area of residence, household income, smoking amount, second-hand smoking, number of attempts to quit, and number of chronic diseases. ${ }^{12,13)}$ In this study, we analyzed the factors associated with the intention of smoking cessation by including new variables to the variables already explored, particularly the history of smoking-related diseases.

We found that $26.3 \%$ of all participants had smoking cessation intentions. However, this percentage was lower as compared to other adult age groups. This could be because older adults are unfamiliar with new-age media technologies and unaware of the available resources, such as smoking cessation programs and support projects. ${ }^{7)}$ In addition, elderly smokers who are highly addicted to nicotine and habituated to long-term smoking tend to think that smoking is not harmful to health. ${ }^{6)}$ Besides, they may have a misperception that health benefits from smoking cessation will be small because their health is already severely damaged. ${ }^{8)}$

Among the health-related characteristics, an important factor known to be associated with the intention to quit smoking is the histo- ry of smoking-related diseases. Several studies have previously reported that patients who were diagnosed with smoking-related diseases were more likely to quit smoking. ${ }^{14,15)}$ In the multivariable analysis of our study, smoking cessation intention significantly increased in elderly smokers who had a history of ischemic heart disease among several smoking-related diseases, which is consistent with previous studies. Salive et al. ${ }^{14)}$ reported that older smokers diagnosed with myocardial infarction, stroke, and cancer were twice as likely to quit smoking. Further, a study by Twardella et al. ${ }^{15)}$ demonstrated that a history of myocardial infarction and stroke increased the probability of quitting smoking during the diagnosis year by 7-11 times than any other socioeconomic factor (e.g., sex, smoking pattern, and education level). A major reason for the increase in the intention to quit smoking in patients with a history of smoking-related diseases is their experience of life-threatening symptoms, intensive care unit treatment, or surgery. ${ }^{16)}$ The burden of expensive treatment during these experiences also strengthens the motivation and willingness to quit smoking. ${ }^{17)}$

It is also known that the high rate of quitting smoking in patients right after the diagnosis of smoking-related diseases decreases with time because of symptom relief and tobacco addiction. ${ }^{17,18)}$ These results demonstrate that patients who have been diagnosed with smoking-related illnesses should actively seek treatment for smoking cessation at the ward or outpatient clinic, and subsequent management and follow-up are necessary to maintain smoking cessation. However, statistics show that only $60 \%$ of the physicians were aware of smoking cessation programs and only about one-half to two-thirds provided assistance, and fewer than a quarter arranged follow-up. ${ }^{19)}$ These results indicate the physicians' negative beliefs about smoking cessation programs. One study showed that physicians have negative attitudes toward smoking cessation programs as they consider it time-consuming and ineffective, and lack confidence in their skills. ${ }^{20)}$ Therefore, in order to increase smoking cessation intervention, specialized training is needed for physicians to improve their specific skills and change their negative beliefs about smoking cessation programs.

We found that more than $60 \%$ of the participants diagnosed with stroke, cancer, ischemic heart disease, and COPD had no plans to quit smoking, which is consistent with previous findings and an alarming rate to consider. ${ }^{21,22)} \mathrm{A}$ large proportion of patients with severe smoking-related diseases have no smoking cessation intention because they believe that it is too late to quit smoking after diagnosis as their health is already severely damaged. ${ }^{23)}$ Besides, some patients are seeking to overcome stress, depression, and pain from their illness by smoking, and some believe that smoking-related diseases are not caused by tobacco. ${ }^{24-26)}$ Since smoking-related diseases are caused by long-term smoking, patients suffering from these diseases are more addicted to nicotine than those suffering from other diseases. ${ }^{23)}$ Especially in COPD, patients continue to smoke because the respiratory symptoms progress slowly and are not severe enough to quit smoking. ${ }^{27)}$

This study assessed the intention to quit smoking through a single question, but it should be approached through a trans-theoretical model. In this model, change is divided into five stages: precontempla- 
tion, contemplation, preparation, action, and maintenance. ${ }^{10)}$ At the precontemplation stage, patients have no intention to quit smoking and are ambivalent or reluctant about changing their use of tobacco. They are also in denial and lack awareness of their smoking problems. Motivational interviewing (MI), which is an evidence-based approach using the stages of change model as a framework, ${ }^{28)}$ has been reported as effective in tobacco cessation. ${ }^{29)}$ The major strategy of MI, which is to move the patient from the precontemplation to the contemplation stage, involves raising doubts and increasing the patient's perception of risk and problems with their current behavior. ${ }^{28)}$ Physicians should actively use MI to increase the intention of precontemplators to quit smoking.

This study has several limitations. First, since this is a cross-sectional study, it was difficult to derive the intention to quit smoking from the related factors. Second, because this study is a secondary analysis, there were limitations in selecting and constructing variables that affect the intention of smoking cessation. We could not use various factors such as smoking cessation policies, nicotine dependence, awareness of smoking and smoking cessation, and tobacco price, among others. In particular, it is worth noting that we could not add cognitive factors such as change process, decision-making balance, and self-efficacy affecting the change stage of smoking cessation in the trans-theoretical model. Third, the sample size $(n=813)$ of our study was relatively small as we limited the study participants to elderly Korean male smokers over 65 years of age. Fourth, recall bias may have occurred because the KNHANES was based on self-reported questionnaires.

Despite these limitations, this study has several advantages. First, the study used data from the KNHANES, which is representative of the Korean population. Second, since there is little research on the intention to quit smoking in elderly Korean smokers, this study has raised the necessity of research on older adults' smoking and provided basic data for establishing a strategy for smoking cessation, especially for older adults.

In conclusion, $26.3 \%$ of the elderly Korean male smokers had the intention to quit smoking, which was lower than that in other age groups. Factors significantly associated with smoking cessation intentions of the elderly Korean male sm okers were a history of ischemic heart disease or cancer. Identifying the factors related to the intention to quit smoking among elderly smokers may be helpful in developing smoking cessation programs or policies for older adults. Based on the results of this study, we suggest the following strategies. First, it is necessary to develop specialized educational programs that promote the intention of smoking cessation and increase quitting attempts in older adults. Second, it is important to communicate through the media the harmful effects of tobacco as well as the health benefits of smoking cessation in order to change the misperceptions of older adults. Third, policies and investments, such as smoking cessation education and support projects, are needed to facilitate the accessibility of resources for older adults. Fourth, further research should increase the number of participants to generalize these findings and include cognitive factors that may influence smoking cessation intentions.

\section{CONFLICT OF INTEREST}

No potential conflict of interest relevant to this article was reported.

\section{ORCID}

Inho Lee: https://orcid.org/0000-0003-2311-8493

Yong Soon Park: https://orcid.org/0000-0002-8926-9836

Jeong Hyeon Kim: https://orcid.org/0000-0002-8889-4437

Seung Hyeok Han: https://orcid.org/0000-0001-7268-2109

\section{REFERENCES}

1. Gellert C, Schottker B, Brenner H. Smoking and all-cause mortality in older people: systematic review and meta-analysis. Arch Intern Med 2012;172:837-44.

2. Statistics Korea. 2017 Statistics on the aged [Internet]. Daejeon: Statistics Korea; 2017 [cited 2018 May18]. Available from: http://kostat.go. kr/portal/eng/pressReleases/11/3/index.board.

3. Ministry of Health and Welfare; Korea Centers for Disease Control and Prevention. 2017 Survey of the living conditions and welfare needs of Korean older persons [Internet]. Cheongju: Korea Centers for Disease Control and Prevention; 2018 [cited 2018 Jun 22]. Available from: http://www.mohw.go.kr/react/jb/sjb030301ls.jsp?PAR_MENU_ID= 03\&MENU_ID=032901.

4. Kang HY, Kim HJ, Park TK, Jee SH, Nam CM, Park HW. Economic burden of smoking in Korea. Tob Control 2003;12:37-44.

5. Ministry of Health and Welfare; Korea Centers for Disease Control and Prevention. 2016 Korea health statistics: Korea National Health and Nutrition Examination Survey (KNHANES VII-1) [Internet]. Cheongju: Korea Centers for Disease Control and Prevention; 2018 [cited 2018 Jun 27]. Available from: https://knhanes.cdc.go.kr/knhanes/sub04/ sub04_03.do? classType=7.

6. Hall SM, Humfleet GL, Gorecki JA, Munoz RF, Reus VI, Prochaska JJ. Older versus younger treatment-seeking smokers: differences in smoking behavior, drug and alcohol use, and psychosocial and physical functioning. Nicotine Tob Res 2008;10:463-70.

7. Abdullah AS, Ho LM, Kwan YH, Cheung WL, McGhee SM, Chan WH. Promoting smoking cessation among the elderly: what are the predictors of intention to quit and successful quitting? J Aging Health 2006; 18:552-64.

8. Appel DW, Aldrich TK. Smoking cessation in the elderly. Clin Geriatr Med 2003;19:77-100.

9. Wu J, Sin DD. Improved patient outcome with smoking cessation: when is it too late? Int J Chron Obstruct Pulmon Dis 2011;6:259-67.

10. Prochaska JO, DiClemente CC, Norcross JC. In search of how people change: applications to addictive behaviors. Am Psychol 1992;47:110214.

11. Zhou X, Nonnemaker J, Sherrill B, Gilsenan AW, Coste F, West R. Attempts to quit smoking and relapse: factors associated with success or failure from the ATTEMPT cohort study. Addict Behav 2009;34:365-73.

12. Ryu SY, Shin JH, Kang MG, Park J. Factors associated with intention to quit smoking among male smokers in 13 communities in Honam region of Korea: 2010 Community Health Survey. Korean J Health Educ 
Promot 2011;28:75-85.

13. Bae JH, Do ES, Seo YS. Factors influencing intention to quit smoking in stroke patients: based on the theory of planned behavior. J Korean Gerontol Nurs 2014;16:49-58.

14. Salive ME, Cornoni-Huntley J, LaCroix AZ, Ostfeld AM, Wallace RB, Hennekens $\mathrm{CH}$. Predictors of smoking cessation and relapse in older adults. Am J Public Health 1992;82:1268-71.

15. Twardella D, Loew M, Rothenbacher D, Stegmaier C, Ziegler H, Brenner $\mathrm{H}$. The diagnosis of a smoking-related disease is a prominent trigger for smoking cessation in a retrospective cohort study. J Clin Epidemiol 2006;59:82-9.

16. Rigotti NA, McKool KM, Shiffman S. Predictors of smoking cessation after coronary artery bypass graft surgery: results of a randomized trial with 5-year follow-up. Ann Intern Med 1994;120:287-93.

17. Martinson BC, O'Connor PJ, Pronk NP, Rolnick SJ. Smoking cessation attempts in relation to prior health care charges: the effect of antecedent smoking-related symptoms? Am J Health Promot 2003;18:125-32.

18. Cox LS, Africano NL, Tercyak KP, Taylor KL. Nicotine dependence treatment for patients with cancer. Cancer 2003;98:632-44.

19. Tong EK, Strouse R, Hall J, Kovac M, Schroeder SA. National survey of U.S. health professionals' smoking prevalence, cessation practices, and beliefs. Nicotine Tob Res 2010;12:724-33.

20. Vogt F, Hall S, Marteau TM. General practitioners' and family physicians' negative beliefs and attitudes towards discussing smoking cessation with patients: a systematic review. Addiction 2005;100:1423-31.

21. Tseng TS, Lin HY, Moody-Thomas S, Martin M, Chen T. Who tended to continue smoking after cancer diagnosis: the National Health and Nu- trition Examination Survey 1999-2008. BMC Public Health 2012;12: 784 .

22. Kim HE, Song YM, Kim BK, Park YS, Kim MH. Factors associated with persistent smoking after the diagnosis of cardiovascular disease. Korean J Fam Med 2013;34:160-8.

23. McBride CM, Ostroff JS. Teachable moments for promoting smoking cessation: the context of cancer care and survivorship. Cancer Control 2003;10:325-33.

24. McCarthy MJ, Huguet N, Newsom JT, Kaplan MS, McFarland BH. Predictors of smoking patterns after first stroke. Soc Work Health Care 2013;52:467-82

25. Daniel M, Keefe FJ, Lyna P, Peterson B, Garst J, Kelley M, et al. Persistent smoking after a diagnosis of lung cancer is associated with higher reported pain levels. J Pain 2009;10:323-8.

26. Schnoll RA, Rothman RL, Lerman C, Miller SM, Newman H, Movsas B, et al. Comparing cancer patients who enroll in a smoking cessation program at a comprehensive cancer center with those who decline enrollment. Head Neck 2004;26:278-86.

27. Wilson JS, Elborn JS, Fitzsimons D. 'It's not worth stopping now': why do smokers with chronic obstructive pulmonary disease continue to smoke?: a qualitative study. J Clin Nurs 2011;20:819-27.

28. Miller WR, Rollnick S. Motivational interviewing: preparing people for change. 2nd ed. New York (NY): Guilford Press; 2002.

29. Lundahl B, Burke BL. The effectiveness and applicability of motivational interviewing: a practice-friendly review of four meta-analyses. J Clin Psychol 2009;65:1232-45. 